\title{
1 Motherhood in migration: a focus on family language planning
}

Introduction

4

The rise in international female migrants and the gendered aspect of migration became the foci

5 of research in the mid-80s (Takeda, 2012). It was around the same time that Brazil, traditionally a

6 host country to international migration, started to produce a significant number of emigrants due to

7 its population's search for work opportunities abroad. According to the Brazilian 2010 census,

$854 \%$ of their nationals living abroad were women (IBGE, 2011a). Since then, a number of studies

9 on gender have been conducted with this group (e.g. de Oliveira Assis, 2014; Colleagues and 10 author, 2013).

Many of these studies on Brazilian female international migrants have focused on issues of race and the labour market. This article contributes to the discussions on gender, and in particular motherhood, by adding a sociolinguistic perspective on the experiences of these migrants. It aims

14 to explore the links between identity (i.e. the positions occupied by individuals in social contexts)

15 and language planning (i.e. the choices made about language use, such as which language is to be used with whom, where and when) from the perspective of a group of Brazilian mothers who are

17 raising their children in London. It draws on data from my doctoral study and addresses the 18 implications of migratory flows for mothering ${ }^{1}$ by asking the following questions: How are the

19 linguistic and cultural identities of a group of Brazilian mothers affected by migration to the UK?

20 What is the impact of these mothers' sense of identity on their family language planning?

\footnotetext{
${ }^{1}$ Please note that "mothering" and "motherhood" are interchangeably used in this article to mean the individual practices and experiences of being a mother. These terms have, however, been used to differentiate between one's experiences (mothering) and one's state (motherhood), see e.g. O'Reilly (2004).
} 
2 Social psychology and poststructuralism constitute the theoretical background to this article, 3 which is presented in two parts. Firstly, the linguistic and the cultural identities of the participant 4 mothers are examined. Secondly, links are made between these identities and the participants'

5 language planning. The analysis is situated within the family domain and centres on issues of 6 motherhood and family language planning (i.e. the choices made by parents in relation to what 7 language to use, when and to whom in raising their children). To conclude, I argue that language 8 choice seems to be essential to these mothers in maintaining their sense of group identity as much 9 as in having a positive sense of motherhood. Therefore, the importance of research on the 10 intergenerational transmission of language to ensure that migrant mothers have positive feelings of 11 motherhood is highlighted, as is the relevance of acknowledging the fathers' role in family 12 language planning and practices.

14 Literature Review:

\section{Language as an identity marker}

17 The concept of identity adopted here reflects a combination of contributions from both social psychology and poststructuralism. Tajfel's (1978) Theory of Social Identity argues that members

19 of different minority groups relate to the host society in three possible ways: by trying to assume

20 characteristics of the local norms, by rejecting the local norms or by retaining some of their own

21 characteristics and acquiring some of the local group. Despite being criticized for presenting a

22 static and fixed view of identity (Rudmin, 2003), the Theory of Social Identity is relevant to the

23 data being considered in this article for two reasons. Firstly, it highlights the effect that coming

24 into contact with the "other" has on identities. It is by meeting the "other" that individuals make 

comparisons between their groups and those of others, which results in awareness of their

2 differences and similarities, leading to the construction of their own social identities (Tajfel, 3 1978). Secondly, the Theory of Social Identity emphasizes the emotional significance of identity 4 to individuals. In fact, Tajfel (1981) presents social identity as being the result of the knowledge of 5 membership together with the emotional significance linked to this membership. Ethnicity (i.e. 6 group cultural characteristics, Hutchinson \& Smith, 1996), gender and language are among the 7 aspects that may be considered fundamental to defining the identity of a group. However, the 8 significance of the different aspects may vary from group to group.

9 Language, for example, has been reported to be highly important in maintaining a sense of 10 identity for some groups, but may not be central for others. The possible (lack of) link between 11 language and identity has been further explored by poststructuralist researchers, such as Bonny 12 Norton. Norton (2000) researched second language acquisition with a group of immigrant women 13 in Canada and observed that high levels of motivation were not readily translated into good levels 14 of language learning. This observation led her to develop the concept of "investment", i.e. a notion 15 which assumes that individuals are motivated to learn a language because it will enable them to 16 have more symbolic and material resources, and thus, more cultural capital to negotiate their 17 identities in society. Furthermore, investment is a construct that conceives of the speaker, in this 18 case a language learner, as having a complex identity which changes across time and space and 19 which is reproduced in social interaction. In this way, a person's identity must always be 20 understood in relational terms, i.e. individuals have more or less power of negotiation depending 21 on the situation in which they find themselves and on the people with whom they interact (Norton, 22 2013). In sum, identity, from a poststructuralist perspective, is a process of negotiating social 23 relations in specific social contexts, and thus, relates to socially constructed categories. 
In cultural studies, Ang (2001) points out that the redefinition of one's social identity is a

2 process commonly faced by migrants in consequence of having entered a new social context. This

3 position reflects both the social psychological view that identities become salient when one

4 encounters the "other" and the poststructuralist view that identities are always in the making. An

5 illustration of this is the description that one of the mothers, Durvalina, gives of her experience of

6 migration as the feeling of being a replanted tree whose roots were once in Brazil. A similar

7 metaphor was used by Tu Wei-ming (1994 in Ang, 2001:45) in his collection The Living Tree:

8 The Changing Meaning of Being Chinese Today. However, Ang (2001) considers the metaphor of

9 the living tree naïve in describing the decentralization of cultural China from geopolitical China.

10 In her view, the metaphor reinforces the dependency of the "new branches of the tree" (cultural

11 China) on its "roots" (geopolitical China), which is contradictory to the idea of decentralization.

12 The metaphor used by Durvalina, however, differs slightly from the one used by Tu Wei-ming

13 (op.cit.). Here she refers to a tree which grew and formed its solid trunk through roots which were

14 fed and made strong in Brazil. The tree, together with its roots, has been replanted in England. It is

15 in England that it changes and develops new branches. Clearly there is a dependence of the

16 periphery on the centre. However, the centre is not there (the place of origin) anymore. The centre

17 is a result of the interaction between the roots which were made strong there and the soil here (the

18 hosting place) that enables the tree to stay alive and continue to grow. In other words, the 19 metaphor of a "replanted tree" refers to the notion of "hybridity", i.e. the appearance of new 20 identities which result from the mix of other identities (Bhabha, 1994).

21 This interaction between there and here is experienced by all the Brazilian mothers being

22 reported. Therefore, this article explores the there-here interaction that leads these Brazilian

23 mothers to develop a sense of being "replanted trees" and examines how this new sense of identity

24 impacts on the language planning they adopt for their families. 


\section{Family language planning}

Family is one of the domains in which language management and negotiation take place, a recognition which has led to family language policy (FLP) as a new area of research within language planning and policy (LPP) (Li Wei, 2012). FLP is situated within a micro perspective of LPP and has been defined as "a deliberate attempt at practising a particular language use pattern and particular literacy practices within home domains and among family members" (CurdtChristiansen, 2009: 352). Many of the studies on FLP, however, focus primarily on mothers: an example being King and Fogle's (2006) study on how decisions about language use with children are made. Although the participants in this study are generally referred to as families and parents, $87.5 \%$ of them are mothers. In other words, mothers appear here as the parent who tends to take the responsibility for their children's acquisition of language, as generally assumed and expected by society. In fact, King and Fogle argue that social pressure plays an important role in decisions about FLP. In their study of families in the USA who are trying to raise their children in two languages (i.e. English and Spanish), both public discourse and personal networks are considered sources of social pressure on FLP. In addition, the analysis shows that, before decisions are made about FLP, these two sources are considered against personal experiences of language learning, be it a second language (i.e. the official language of a country which is learned by migrants), a foreign language (i.e. the official language of a country which is learned by individuals who live in another country) or a heritage language (i.e. passed down by parents of migrant backgrounds and also commonly referred to as community language). In the case of the Brazilian mothers discussed in the present article, both public discourses and personal networks are mentioned as being influential in their FLP. However, their own language learning experiences are only mentioned by those who learned Portuguese as a heritage language. This seems to indicate that the 
1

4

5 As a consequence, these mothers consider multilingualism to be a key characteristic of being 6 Luxembourgers. Nevertheless, they strongly identify with Luxembourgish as being their 7 emotional and national language. It means that, when living in England, these mothers explicitly 8 plan their language use in order to ensure that their children grow up as bilinguals in 9 Luxembourgish and English. These mothers' beliefs in the benefits of bilingualism, however,

\footnotetext{
${ }^{2}$ All quotations by the Brazilian mothers were originally in Portuguese and are my translations.
} 
their sense of self' (p.162). To the group of Pakistani women, being a mother meant fostering the

2 use of their mother tongue with and by their children as much as fostering the values of their

3 religion and other ethnic markers, as well as promoting English for educational purposes.

4 Maintaining the use of their mother tongue signalled their attachment to their heritage group, their

5 cultural and religious values. Furthermore, these women believed that these values and identity

6 would be acquired by their children by the mere fact of speaking their mother tongue. This is the

7 reason why they considered it important to pass on their language to their children. In other words,

8 language is an essential part of these women's identity as individuals as much as mothers. It is

9 crucial for these mothers that their language is passed on to their children. This same link between

10 language choices, notions of mothering and sense of identity can be seen among the Brazilian

11 mothers and is explored below.

13 Methodology

\section{A group of Brazilian mothers}

The UK is one of the main destinations for Brazilians in Europe and over six per cent of all Brazilian emigrants are in England (IBGE, 2011b), with their highest concentration being in

17 London. It is also in London where the first Brazilian Portuguese language school started its

18 activity in the late 90s and where the largest number of these schools can be found now (Author 19 and colleague, 2014). It is within the context of one of these schools (henceforth referred to as

20 CLS, i.e. community language school) that the data discussed were collected.

21 Except for two, all the families taking their children to the CLS in question were made up of

22 Brazilian mothers and fathers of other nationalities. In other words, in most of these families the

23 Brazilian parent was the mother. In order to reflect this characteristic of the families in this 
context, a total of nine Brazilian mothers, three in each of the three classes run by the school at the

2 time of my doctoral study, were invited to participate.

\section{Individual and group interviews}

5 The mothers were interviewed at two stages, first in individual semi-structured interviews and

6 then in group interviews. The semi-structured interviews served the purpose of drawing a profile

7 of the mothers in relation to their socio-economic, educational and linguistic backgrounds. With

8 this in mind, an interview schedule was designed and used to record individual interviews which

9 lasted about one hour each.

Focus group interviews were then used with the intention of obtaining insights into the reasons

11 behind the opinions the mothers expressed in the first set of interviews. More specifically, these

12 two-hour interviews aimed at gaining an insider's view about the mothers' sense of ethnicity, their

13 collective goals in relation to the host society, their language attitudes and use.

14 Ethical issues were carefully considered in the design and conduct of these interviews.

15 Informed consent was obtained from the mothers, who were assured of my commitment to their

16 rights to confidentiality. The names used in this article are pseudonyms. Additionally, the mothers

17 themselves were asked to keep any information shared during the discussions confidential. In this

18 way we shared responsibility for the ethical issues involved in the group interviews. I also pointed

19 out to the mothers the importance of respecting each other's opinions during the focus interviews,

20 due to the emotional weight of the discussion of issues relating to identity. It also meant I had to

21 be careful about the probing used in order to find a balance between eliciting useful information

22 and not causing emotional harm to the participants.

23 Moreover, it is important to highlight that I am a Brazilian female migrant in London and all

24 the mothers knew me from my volunteer work at the CLS as a teaching assistant. In order to 
1 reduce the possible biases my position could impose on the research, I openly dealt with these

2 issues. At the start of the individual interviews, I acknowledged my migrant and teaching 3 backgrounds and emphasised the importance of the mothers' individual contributions to the 4 questions being explored. For the group interviews, I absented myself from the discussions, and 5 instead, I merely facilitated the interactions between the mothers. This attitude also applied to the 6 exploration of concepts (e.g. ethnicity and hybridity) and the participants were asked to present 7 their own interpretations and understandings of their meanings. All in all, my aim was to 8 understand the perspectives and the experiences of the participating mothers.

\section{Constructing profiles and creating composite files}

The data provided by each participant in the semi-structured interviews were initially recorded individually in the interview schedule. In general terms, the mothers were aged between 30 and 50 and had been living in the UK for at least 10 years. They represented small families with an average of two children, from 10 months to 12 years old. The mothers' level of education varied from having only completed primary school to holding a university degree. Their occupations also varied from being unemployed to holding highly skilled professional jobs.

A profile was written for each of the mothers and covered how they think of themselves in relation to the majority society, how important their ethnic identity is to them and the importance

19 of the different components of their social identities. This profile was then added to the analysis of 20 the semi-structured interviews described above and a composite file was produced for each 21 mother.

22 How the mothers' linguistic and cultural identities are affected upon migration to the UK and

23 how these identities affect their family language planning are discussed in detail in the results section of this article. 


\section{Results}

3

\section{Mothers' linguistic and cultural identities}

5 The way in which the Brazilian mothers refer to their linguistic and cultural identities is 6 multiple and changeable according to context. Nevertheless, their social profiles appear to 7 generally refer to the three types of Tajfel's (1978) inter-group interaction. I match these types of

8 interaction to the terminology used by Hannerz (2000): (1) going "native" (i.e. individuals who

9 expect to be able to assimilate into the majority group), (2) remaining "tourists" (i.e. the ones who 10 are against assimilation and therefore maintain superficial contacts with the local culture) or, (3)

11 becoming "cosmopolitans" (i.e. the members who manage to participate in the majority group

12 without being readily identified as not belonging due to their involvement with a plurality of 13 different cultures). Furthermore, Block (2002)'s subdivision of cosmopolitans into "early 14 cosmopolitans" (who immigrate as children) and "expatriate cosmopolitans" (adults who spend a

15 long period of time abroad) are also applied. I place the four types of identification in an identity 16 continuum. This means that I select a general term to refer to these mothers based on the social 17 profiles they provided in the semi-structured and in the focus interviews, despite being aware that 18 their identities might vary according to social contexts.

19 Dorotéa, Durvalina and Aparecida are the mothers whose children attended the CLS for the 20 longest period of time. Dorotéa appears to relate to British society in a way which tends to lie at 21 the "tourist" extreme of the continuum. In other words, she does not participate in the local society

22 except for issues related to her daughter. Her social and economic links are with the Brazilian 23 community and she self-identifies as being Brazilian. 
Durvalina also self-identifies as Brazilian but relates to the local society in a different way to

2 Dorotéa. In her interviews, Durvalina selects characteristics which she considers positive from

3 both the minority and the majority societies, which places her towards the "expatriate

4 cosmopolitan" type in the identity continuum.

5 Aparecida, on the other hand, has stronger emotional links to British society than Dorotéa and

6 Durvalina. In contrast to the other two mothers, Aparecida grew up in England and experienced

7 life in the UK from a young age, which places her towards the "early cosmopolitan" type in the

8 identity continuum. Like Durvalina, Aparecida has a "hybrid" identity; however, the boundaries

9 between her Brazilian and her English identities are more blurred, especially emotionally

10 speaking.

11 The other six mothers whose children attended the CLS lessons for a period of time in their

12 lives can be analysed by drawing on the same categorizaton of inter-group interaction. Carmélia,

13 like Dorotéa, tends towards the "tourist" type in the identity continuum in the sense that she does

14 not make an effort to be involved in British society. Notwithstanding, Carmélia has links with the

15 host society through her work as a childminder, her children's school and her housing association.

16 Her involvement with the Brazilian community takes place through the CLS and she believes she

17 expresses herself better in Portuguese.

Efigênia, Lindalva and Rogéria self-identify in a similar way to Durvalina, towards the "expatriate cosmopolitan" type along the identity continuum. Efigênia is one of the few participants who reports making an effort to be involved with the Brazilian community in London.

21 She consciously made this decision because she realized her son started to lose his Portuguese

22 when he entered school. In spite of her involvement with the Brazilian community, Efigênia also

23 considers it important to be part of British society and does not avoid being influenced by it. 
1 while continuing to be Brazilian. She describes integration as "being able to experience your daily

2 life without attrition with the culture where you live and yet preserve your own culture". However,

3 Lindalva had difficulties pinpointing markers of her Brazilian ethnicity, an illustration of the fact

4 that ethnicity is an unconscious process, which is, therefore, difficult to bring to the surface.

5 Further to feeling Brazilian, Lindalva refers to behavioural issues as markers of her ethnicity. She

6 mentions kissing people on the cheek when greeting them, having close family links as well as

7 connections with Brazil and the role food plays in Brazilian social life.

8 Rogéria also mentions behavioural characteristics, such as being tactile, cuddling her children a

9 lot and routinely being joined by friends and their children for meals at home, as markers of her

10 Brazilian ethnicity. Rogéria recognizes it is difficult not to be influenced by the local community

11 and states that there is a need to be aware of how the majority group behaves in order to carry out

12 your daily tasks. She reports that speaking Portuguese is part of who she is.

Raimunda and Túlia, two mothers whose self-identity tends towards the "early cosmopolitan" type in the identity continuum, had different experiences in growing up in a foreign country and the way they relate to the Portuguese language. Raimunda grew up in a bilingual environment where she would speak Portuguese to her family and another language to the other people in her social network. She reports having kept her Brazilian ethnicity due to her mother's efforts to pass it on to her. Raimunda refers to being born in Brazil and speaking Portuguese as markers of her ethnicity. She refers to the way she sees the world as well as the way she behaves and her identification with the Brazilian culture as inheritances from her mother.

21 Túlia also refers to the importance of her mother in relation to her links with Brazilian culture.

22 Like Raimunda, when describing her "Brazilianness", she mentions her experiences in Brazil

23 during her childhood as well as the closeness between the family members and the family's

24 presence in her daily life. However, Túlia's experiences in the majority society have led her to 
1 value being able to speak "proper" English in order to be accepted. Túlia's learning of English

2 seems to be full of emotional baggage. She met her husband when she first arrived in England and

3 learned English as their relationship developed.

4 All in all, the nine Brazilian women in this article have acquired some characteristics from the 5 majority society but they still feel as if they are and behave as Brazilians. In other words, being 6 born in Brazil (Y1) and speaking Brazilian Portuguese as their first language (Y2) allows the 7 mothers to see themselves as Brazilians. This identity is then affected in different degrees when 8 they move to England (X1) and learn to speak English (X2). This new identity, which results from 9 the interaction between their experiences of growing up in Brazil and speaking Portuguese (Y) and 10 their experiences in England and speaking English (X), is what I call, borrowing my participant's 11 image, "replanted tree" identity $(\mathrm{Y}+)$, as illustrated in Figure 1 below.

17

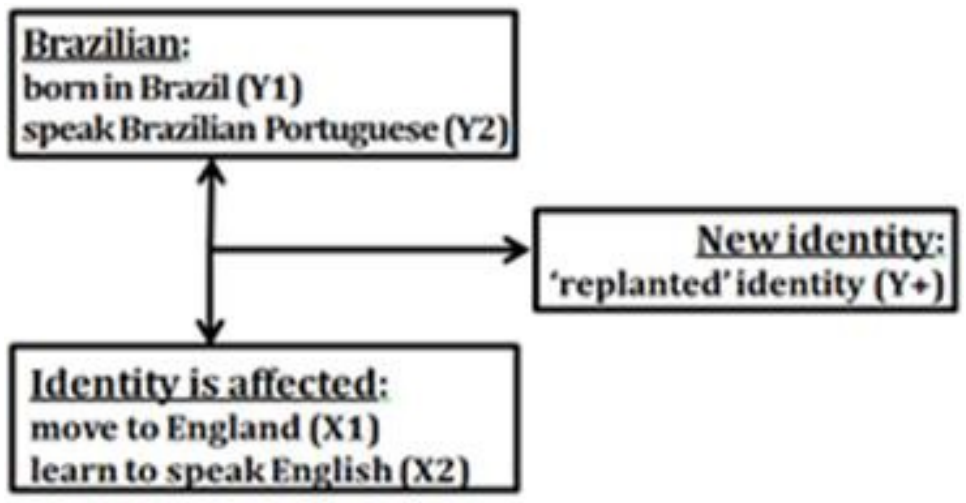

Figure 1 - Replanted Tree Identity

Having examined issues of identity from the perspective of a group of Brazilian mothers, I now turn to how these issues impact on their family language planning.

\section{Identities and family language planning}


The data collected indicate that the varied ways in which the Brazilian mothers refer to their

2 linguistic and cultural identities have implications on the way languages are used in their homes.

3 Dorotéa, one of the "tourist" mothers, never studied English formally and admitted not making

4 efforts to improve her language skills. According to her, "speaking Portuguese is important

5 because it is [her] language". Despite being proud of her daughter's bilingual skills, Dorotéa

6 claims to only speak Portuguese to her. Dorotéa's family domain is conducive to the use of

7 Portuguese also because her niece, who does not speak English, is her lodger. It means that the use

8 of English would prevent communication in the household and creates an environment where the

9 use of Portuguese is not only desirable but also necessary. In addition, the use of Portuguese is

10 validated by Dorotéa's husband, who is also a speaker of Portuguese.

11 Carmélia, the other "tourist" mother, did not learn English formally and states that she 12 expresses herself better in Portuguese. Her husband, however, does not speak Portuguese. Besides

13 communicating with her in English only, he stopped her speaking Portuguese to their children

14 until they were four years old. This imposed FLP has now been negotiated and the children were

15 allowed to attend the CLS at an older age. It means that, in spite of her wishes, Carmélia's use of

16 Portuguese with her children has been limited and seems to have been restricted to the giving of

17 instructions.

18 The use of languages in the household of the three "expatriate cosmopolitans" appears to be 19 more varied. Durvalina, for example, claims to speak both Portuguese and English with her son.

20 The use of Portuguese in her household is possible for two reasons. Firstly, Durvalina rents out

21 rooms to other Brazilians and they communicate with each other in Portuguese. Secondly,

22 Durvalina's husband understands Portuguese well, which allows for the use of both languages

23 without any conflict. Portuguese is used between Durvalina, her Brazilian lodgers and her son.

24 English is used between Durvalina's husband, the lodgers and her son. Furthermore, Durvalina has 
made a conscious decision to formally educate her son in both Portuguese and English. The boy

2 attends lessons in an English mainstream school as well as in the Brazilian CLS.

Efigênia, the second "expatriate" mother, clearly identified the mother-child relationship as a

4

5

6

7

reason for her investment in her son's ability to speak Portuguese. She has always spoken to him in Portuguese, a choice supported by her husband who is non-Brazilian but can speak the language. Efigênia's son interacted with her in Portuguese but started to lose his ability to use it when he joined an English mainstream school. Efigennia explains that the fact that her son no longer spoke Portuguese made her feel distant from him, so she became involved in the Brazilian community and the CLS, in order to offer him more opportunities to learn her first language.

The other two "expatriate" mothers present a very similar context to Efigênia's. They are both married to English-speaking fathers who are open to Brazilian culture and have positive attitudes to the Portuguese language. As a consequence, both Portuguese and English are used in their households. Nevertheless, the monolingual pressures of British society negatively affect their children's use of Portuguese. In order to counter these pressures, both mothers enrolled their children in the Brazilian CLS. After all, from Lindalva's perspective, "[y]ou are not Brazilian if you can't speak Portuguese. It doesn't make sense for the mother to speak Portuguese and the children not". An opinion reinforced by Rogéria:

"Portuguese is my language. And my children are half-Brazilian. So, I find it terrible when I hear someone say 'My mother is Brazilian' but they can't say a single word in Portuguese. It reflects on me. I feel so embarrassed!"

In the case of the "early expatriate" mothers, the decision to take their children to the CLS is a measure used to counter the negative pressures of British society on bilingualism as much as to counter their feelings of having failed as mothers for being unable to adopt a FLP which is supportive of their children's use of Portuguese with them. Aparecida is married to an English 

speaker who is also fluent in Portuguese. In spite of Aparecida's husband's competence in

2 Portuguese and positive attitudes to both Brazilian culture and the Portuguese language, English is the only language used in their household. Aparecida explains her involvement with the CLS to

4 compensate for her FLP in the following quote: "I want my children to be able to speak

5 Portuguese, but I don't manage (to communicate with them in Portuguese). I think that's why I got

6 involved (with the complementary school)". Aparecida's difficulty with using Portuguese to

7 communicate with her children comes from her experience of growing up in a family that had 8 many emotional issues.

9 The second "early expatriate" mother, Túlia, also refers to her emotional links to the English language. In her case, however, these links resulted from learning English as a teenager at the

11 same time that her relationship with her now husband developed. It means that they only speak

12 English to each other and to their children. Nevertheless, the children are exposed to Brazilian culture through music and art. According to Túlia, her mother is the one who contributes to the presence of Brazilian culture and the Portuguese language in her home:

15

"My mother has a great influence in my life. I speak to her on the phone everyday and we see each other once a week. She is the one who has led me to enrol my children in Portuguese lessons and the one who makes an effort to speak to them in Portuguese."

Raimunda, the third "early expatriate" mother, also refers to the influence of her mother in her life. She states that the way she sees the world, the way she behaves, her identification with Brazilian culture and the Portuguese language are inherited from her mother. Raimunda's adopted

FLP reflects her own positive linguistic and cultural experiences. It means that Portuguese is used

between Raimunda and her children, while her husband uses English with her and their children. In addition, the children are developing their English in the mainstream school and their 
1 Portuguese in the Brazilian CLS. The children are also reported to use both English and

2 Portuguese among themselves.

4

\section{Discussion and conclusions}

All in all, the discussions in this section make it clear that migrant mothers address their linguistic emotional needs and educational views by deliberately taking action to manage the pattern of language use in the micro contexts of their homes and social networks.

Albeit to different degrees, the results presented in this article have shown that the Brazilian mothers connect their ethnic identity to the use of Portuguese, which makes relevant the transmission of this language to their children. In Efigênia's own words: "I am Brazilian, I was not born here. My culture is Brazilian. So, Portuguese is important for my child to understand all of these." As a consequence, the geographical distance from Brazil, and therefore from relatives, has led mothers to develop activities through which their children can socialize among themselves and with other adults through the use of Brazilian Portuguese in England. Complementary school attendance is one example of these activities. The schools not only support the children's language development but also reduce the guilt that some of these mothers may feel in relation to not exposing the children enough to Portuguese in their homes.

It is undeniable that terms such as "first-language" and "mother-tongue" show an assumption that one's first language is learned from one's mother, which highlights the role of one parent in language acquisition (Mills, 2004). This role seems to be associated with motherhood in the same way as mothers tend to be allocated the role of primary caregivers. Indeed, mothers appear to take on this responsibility for themselves. It is therefore crucial to explore and offer insights into the experiences of migrant mothers in relation to language transmission, as this article does. It is also a necessary contribution to making women more visible in migration studies. 
However, there is a risk that, when trying to create a space for women in academic studies, 2 men's experiences are wrongly diminished (Boyd \& Grieco, 2003). In my own study, I 3 acknowledge that, not having involved the fathers directly in the investigation, can be seen as a

4 limitation. Yet, although the fathers were not interviewed, their "shadows" were made present 5 throughout the project by the mothers and the children. There were distinct signs that the fathers 6 did play a role in the amount of Portuguese being used at home as well as the amount of exposure 7 the children had to Brazilian culture. Raimunda's husband, for example, understood Portuguese, 8 and was happy for it to be used by his wife and daughters among themselves and to him, although

9 he would reply to them in his mother-tongue. Another positive example is provided by

10 Durvalina's husband, who has travelled to Brazil with the family on many occasions, showing

11 acceptance of the Brazilian culture and enabling his son to be exposed to it. This situation ensured

12 that their son has positive attitudes towards both the Portuguese and the English languages.

There were also indications that the fathers emotionally influenced the children's language 14 attitudes. In the case of Dorotéa, her husband supported their daughter's bilingualism and was the 15 one who drove her to and from the CLS. In addition, as reported by Dorotéa, he was also openly 16 proud of their daughter's language skills. In other words, this father demonstrates positive 17 language attitudes and thus contributes positively to Dorotéa's FLP.

18 The role played by fathers ${ }^{3}$, however, may be a restrictive one, as Carmélia's child suggests: 19 "Dad does not like it when we speak like this". Nevertheless, fathers unquestionably participate in 20 family language planning, even if their involvement is not always explicit. In other words, both 21 parents influence children's language maintenance, albeit in different ways. Luo \& Wiseman's

\footnotetext{
${ }^{3}$ The importance of fathers' role in language maintenance has also been acknowledged by studies on Koreans in New Zealand. In Korean families, children are expected to follow what the fathers set out (Johri, 1998 and Park, 2000 in Kim \& Starks, 2010).
} 
1 (2000) study on Chinese migrants in the US, for example, shows that fathers' attitudes influence

2 language use whereas mothers influence children's level of language proficiency.

In sum, this article uses narrative data to consider aspects of sociolinguistics, more specifically

4 issues of language and identity, to reflect on motherhood in migration. The discussions are based

5 on data collected with a group of Brazilian mothers, a recent group of migrants to the UK. This

6 case study of mothers in intermarriage makes an interesting contribution to the new field of

7 Family Language Policy and ultimately argues that both fathers and mothers should participate

8 equally in the conscious planning of language use. With the aim of better supporting positive

9 experiences of motherhood in migration, further research on FLP should explore the language

10 perspectives of both parents as well as how they negotiate the use of different languages in their

11 household and the transmission of language to their children.

\section{Rheferences}

Ang, Ien (2001). On Not Speaking Chinese: Living Between Asia and the West, London: Routledge.

Bhabha, Homi (1994) The Location of Culture. London: Routledge.

Bdock, David (2002). 'Destabilized identities and cosmopolitanism across language and cultural

17 borders: two case studies' in Hong Kong Journal of Applied Linguistics, 7(2), 1-11.

BBoyd, Monica \& Grieco, Elizabeth (2003). Women and Migration: Incorporating Gender into

19 International Migration Theory. Washington, DC: Migration Policy Institute.

20 http://www.migrationpolicy.org/article/women-and-migration-incorporating-gender-international-

21 migration-theory/ [Accessed on $30^{\text {th }}$ April 2014]

Qurdt-Christiansen, Xiao Lan (2009). Invisible and visible language planning: Ideological factors in

23 the family language policy of Chinese immigrant families in Quebec. Language Policy, 8, 351-

24375.

215 Oliveira Assis, Gláucia (2014). Gender and migration from invisibility to agency: The routes of

26 Brazilian women from transnational towns to the United States, Women's Studies International

27 Forum. http://dx.doi.org/10.1016/j.wsif.2014.01.003Hannerz, Ulf (2000). Transnational

28 Connections. London: Routledge.

29utchinson, John \& Smith, Anthony (1996). Introduction. In John Hutchinson \& Anthony Smith 30 (Eds.), Ethnicity (pp. 3-14). Oxford: Oxford University Press.

3BGE (2011a) Censo 2010: mais da metade dos emigrantes brasileiros são mulheres. Instituto 32 Brasileiro de Geografia e Estatística.

33 http://saladeimprensa.ibge.gov.br/noticias?view=noticia\&id=1\&busca=1\&idnoticia=2017

34 [Accessed on $30^{\text {th }}$ April 2014]

BBGE (2011b) Censo Demográfico 2010 - Características da população e dos domicílios, Resultados 36 do universo. Rio de Janeiro: Instituto Brasileiro de Geografia e Estatística. 
1 http://biblioteca.ibge.gov.br/visualizacao/periodicos/93/cd_2010_caracteristicas_populacao_domic

2 ilios.pdf

Kim, Sun \& Starks, Donna (2010). The role of fathers in language maintenance and language attrition:

4 the case of Korean-English late bilinguals in New Zealand. International Journal of Bilingual

5 Education and Bilingualism, 13(3), 285-301.

KGing, Kendall \& Fogle, Lyn (2006). Bilingual parenting as good parenting: Parents' perspectives on

7 family language policy for additive bilingualism. International Journal of Bilingual Education

8 and Bilingualism, 9: 695-712.

Kirsch, Claudine (2012). Ideologies, struggles and contradictions: an account of mothers raising their 10 children bilingually in Luxembourgish and English in Great Britain, International Journal of

11 Bilingual Education and Bilingualism, 15(1), 95-112. DOI: 10.1080/13670050.2011.607229

1j Wei (2012) Language policy and practice in multilingual, transnational families and beyond.

13 Journal of Multilingual and Multicultural Development, 33(1), 1-2. DOI:

14 10.1080/01434632.2011.638507

15ıo, Shiow-Huey \& Wiseman, Richard (2000). Ethnic language maintenance among Chinese

16 immigrant children in the United States. International Journal of Intercultural Relations, 24(3),

$17 \quad 307-324$.

N\&ills, Jean (2004). Mothers and Mother Tongue: Perspectives on Self-construction by Mothers of 19 Pakistani Heritage. In Aneta Pavlenko \& Adrian Blackledge (Eds.), Negotiation of Identities in

20 Multilingual Contexts (pp. 161-191). Clevedon: Multilingual Matters.

2 Torton, Bonny (2000). Identity and Language Learning: gender, ethnicity and educational change,

22 London: Longman.

ZBorton, Bonny (2013). Identity and Language Learning: Extending the Conversation, London:

24 Longman.

25'Reilly, Andrea (ed.) (2004). From Motherhood to Mothering: The Legacy of Adrienne Rich's Of 26 Woman Born. Albany: State University of New York Press.

RZudmin, Floyd (2003). Critical History of the Acculturation Psychology of Assimilation, Separation, 28 Integration, and Marginalization. Review of General Psychology, 7(1), 3-37.

Taiffel, Henri (1978). The Social Psychology of Minorities. London: Minority Rights Group.

Jajfel, Henri (1981). Human Groups \& Social Categories: studies in social psychology. Cambridge:

31 Cambridge University Press.

52akeda, Atsushi (2012). Emotional transnationalism and emotional flows: Japanese women in

33 Australia. Women's Studies International Forum, 35, 22-28. DOI:10.1016/j.wsif.2011.10.002 